\title{
Three years of sea ice freeboard, snow depth, and ice thickness of the Weddell Sea from Operation IceBridge and CryoSat-2
}

\author{
Ron Kwok and Sahra Kacimi \\ Jet Propulsion Laboratory, California Institute of Technology, Pasadena, California, USA \\ Correspondence: Ron Kwok (ron.kwok@jpl.nasa.gov)
}

Received: 11 May 2018 - Discussion started: 25 May 2018

Revised: 9 August 2018 - Accepted: 21 August 2018 - Published: 30 August 2018

\begin{abstract}
We examine the variability of sea ice freeboard, snow depth, and ice thickness in three years $(2011,2014$, and 2016) of repeat surveys of an IceBridge (OIB) transect across the Weddell Sea. Averaged over this transect, ice thickness ranges from $2.40 \pm 1.07$ (2011) to $2.60 \pm 1.15 \mathrm{~m} \mathrm{(2014) \text {and }}$ snow depth from $35.8 \pm 11.5$ (2016) to $43.6 \pm 10.2 \mathrm{~cm}$ (2014), suggesting a highly variable but broadly thicker ice cover compared to that inferred from drilling and ship-based measurements. Spatially, snow depth and ice thickness are higher in the more deformed ice of the western Weddell. The impact of undersampling the thin end of the snow depth distribution on the regional statistics, due to the resolution of the snow radar, is assessed.

Radar freeboards (uncompensated for snow thickness) from CryoSat-2 (CS-2) sampled along the same transect are consistently higher (by up to $8 \mathrm{~cm}$ ) than those computed using OIB data. This suggests radar scattering that originates above the snow-ice interface, possibly due to salinity in the basal layer of the snow column. Consequently, sea ice thicknesses computed using snow depth estimates solely from differencing OIB and CS-2 freeboards (without snow radar) are therefore generally higher; mean differences in sea ice thickness along a transect are up to $\sim 0.6 \mathrm{~m}$ higher (in 2014). This analysis is relevant to the use of differences between ICESat2 and CS-2 freeboards to estimate snow depth for ice thickness calculations. Our analysis also suggests that, even with these expected biases, this is an improvement over the assumption that snow depth is equal to the total freeboard, with which the underestimation of thickness could be up to a meter. Importantly, better characterization of the source of these biases is critical for obtaining improved estimates and understanding the limits of retrievals of Weddell Sea ice thickness from satellite altimeters.
\end{abstract}

Copyright statement. (C) 2018 California Institute of Technology. Government sponsorship acknowledged.

\section{Introduction}

As snow loading is required for the conversion of freeboard to thickness, the reliable determination of sea ice thickness in the Antarctic remains a challenge largely due to uncertainties in snow depth (e.g., Giles et al., 2008). In the Antarctic, as in the Arctic, estimates of sea ice thickness are necessary to evaluate both stand-alone sea ice and coupled climate models, attribute the causes of recent observed changes, evaluate and understand the physical processes controlling sea ice extent and thickness, and to improve model projections of the future sea ice cover. One distinguishing feature of sea ice in the Antarctic vis-à-vis the Arctic is the common occurrence of snow-ice due to heavier snowfall over Antarctic sea ice (Massom et al., 2001): when snow load depresses the ice surface of the thinner Antarctic sea ice below sea level, seawater infiltrating the base of the snow layer leads to the formation of snow-ice when the resultant slush freezes. The changes in the properties of the snow layer due to the thicker snow cover, flooding, and snow-to-ice conversion complicate the large-scale retrievals of snow depth and ice thickness. In recent efforts to estimate Antarctic sea ice thickness using various estimates of snow depth, a wide discrepancy between ice thickness estimates persists (Yi et al., 2011; Kurtz and Markus, 2012; Xie et al., 2013).

Since 2009, NASA's Operation IceBridge (OIB; Koenig et al., 2010) has flown surveys to acquire spring data over the Arctic and Antarctic sea ice covers. Implemented as an airborne remote sensing program to extend the laser altimeter time series through the gap between the end of the ICESat 
mission and the launch of the ICESat-2 (IS-2) lidar, OIB has acquired a unique time series that allows for examination of the interannual behavior of Antarctic sea ice cover as well as a better understanding of the remote sensing issues associated with the retrieval of sea ice freeboard and thickness. In addition to a lidar to determine freeboard, the OIB instrument suite includes an ultra-wideband radar that is capable of resolving the location of the air-snow and snow-ice interfaces, hence providing snow depth estimates. Over the OIB mission, the sensitivity of snow depth retrievals to associated snow properties (density and salinity) has become a special emphasis because of the significant impact of snow on thickness estimates using lidar or radar (Kwok, 2014). Except for a recent analysis that specifically addressed the variability of OIB snow depths in the Weddell and Bellingshausen seas (Kwok and Maksym, 2014), this OIB data set has received less attention relative to the data acquired over Arctic sea ice. In this paper, we examine the spatial and interannual variability of snow depth and sea ice thickness from the repeat survey of an OIB track in the Weddell Sea and use the combined OIB and CryoSat-2 (CS-2) data to inform the derivation of snow depth and ice thickness from satellite altimetry.

With the planned launch of IS-2 (Markus et al., 2016; scheduled for late 2018) to continue the altimetry time series to inform changes in the cryosphere, there may be a unique opportunity to obtain near-coincident altimetry of the sea ice cover from both a lidar (IS-2) and a radar (CS-2), especially for the extraction of snow depth for thickness calculations. In an analysis using OIB and CS-2 acquisitions over the Arctic Ocean, Kwok and Markus (2017) demonstrated that snow depth can potentially be estimated from differencing the lidar and radar freeboards. Hence, it would be of particular interest if such an analysis approach could be used in the Antarctic as well.

In this paper, we address two topics: (1) the spatial and interannual variability of total freeboard, snow depth, and sea ice thickness in three years $(2011,2014$, and 2016) of repeated IceBridge surveys of a transect across the Weddell Sea and (2) the estimation of sea ice thickness, in the absence of snow depth measurements, using only freeboards from the IS-2 and near-coincident CS-2 radar freeboards. The paper is organized as follows. Section 2 describes the instruments and the data sets used in our analyses. Section 3 outlines the different ways of calculating freeboard, snow depth, and thickness using estimates from lidar and radar freeboards. Section 4 summarizes the spatial and interannual variability of these three sea ice parameters in the three years of OIB data. Section 5 discusses estimates of ice thickness, in the absence of snow depth measurements, using only estimates of freeboard from the ATM lidar and near-coincident CS-2 radar freeboards. The quality of thickness estimates is assessed by comparison with those estimates calculated with the assumption that snow depth is equal to the total freeboard (i.e., zero ice freeboard). Section 6 summarizes the results that are of geophysical interest.

\section{Data description}

The three data sets of interest are the total $($ snow + ice) freeboard from the NASA Airborne Topographic Mapper (ATM), the snow depth estimates from the ultra-wideband snow radar (SR) from OIB, and the radar freeboard from CS2. All through the OIB campaigns, the ATM and SR instruments have been operated simultaneously and provide nearcoincident coverage, albeit at different spatial resolutions. In this section, we provide a brief description of the specifications and coverage of these lidar and radar systems and the quality of the retrievals.

\subsection{IceBridge ATM freeboard}

Surface elevations are from the IceBridge (narrow and wide swath) ATM L1B (lidar) Elevation and Return Strength data set (Krabill, 2014). This data set contains ATM spot elevation measurements $(\sim 1-2 \mathrm{~m}$ footprint $)$ over sea ice. ATM scanning geometry provides an across-track scan swath of $45 / 250 \mathrm{~m}$ with a typical elevation accuracy for individual samples of better than $10 \mathrm{~cm}$. Total freeboards (ice+snow, $h_{\mathrm{f}}$ ), the height of the snow surface above the local sea surface, from the lidar were derived from the IceBridge elevation data using the approach described by Kwok et al. (2012). Sea surface references are identified in highresolution visible imagery acquired by a digital mapping system (Dominguez, 2010). For the analysis here, the total freeboard of an elevation sample is calculated only when open water surfaces (i.e., leads) within $10 \mathrm{~km}$ are present to serve as local sea level reference. We use at least 10 samples (but the population is typically higher) to estimate each sea surface reference, giving a precision of typically better than $3 \mathrm{~cm}$.

\subsection{IceBridge snow depth}

Estimates of snow depth were derived from the IceBridge L1B Radar Echo Strength Profiles data set (Leuschen, 2014) from the snow radar. This frequency-modulated continuouswave (FM-CW) radar is operated by the Center for Remote Sensing of Ice Sheets (CReSIS) at the University of Kansas. The large bandwidth $(\sim 6 \mathrm{GHz})$ provides a range resolution of $\sim 5 \mathrm{~cm}$ (in free space) for resolving the location of the air-snow (a-s) and snow-ice (s-i) interfaces (Panzer et al., 2013). With averaging, the spot separation is $\sim 1 \mathrm{~m}$ along track at an altitude of $\sim 500 \mathrm{~m}$ and an air speed of $\sim 250 \mathrm{kts}$ (the nominal flight parameters for all OIB sea ice surveys). The size of the average footprint is $\sim 5-10 \mathrm{~m}$, and the spacing between the processed radar profiles is $\sim 5 \mathrm{~m}$. The reader is referred to the published literature for a more detailed description of the radar system (e.g., Panzer et al., 2013) and of the data characteristics (e.g., Kwok et al., 2011).

Snow depth is calculated using a simplified version of the retrieval procedure described by Kwok and Maksym (2014) 
that has the capability to compensate for effects due to residual system side lobes in the returns (Kwok and Haas, 2015). A bulk snow density of $320 \mathrm{~kg} \mathrm{~m}^{-3}$ was used to convert the range differences between the air-snow $(\mathrm{a}-\mathrm{s})$ and snow-ice (s-i) interfaces (in free space) to snow depth. Since a reprocessed version of the radar data set with suppressed system side lobes is now available for all years, the aspect of the algorithm that deals with system side lobes has been disabled. In this algorithm (described in Kwok and Maksym, 2014), both the snow-ice and air-snow interfaces are detected and localized by determining the significance of each local peak above the noise floor in individual echo returns. Significance is determined by the strength and width of the local maxima (power) and their associated leading and trailing edges relative to the expected noise power of the system. The system bandwidth controls the width (or sharpness) of a local maximum and the rate of rise of its leading edge. The algorithm uses these system-dependent parameters to adapt to the changes in the radar system as the bandwidth and noise level of the snow radar have progressively improved over the course of the OIB mission. The highest significant peak in the echo profile is designated as the return from the $\mathrm{s}-\mathrm{i}$ interface. Returns from a-s interfaces, determined using the above criteria, are assumed to be weaker than the first significant range returns. Once the interfaces are detected, the radar range to the interface is localized in an oversampled (by 16 times) version of the echo return; this reduces the range error in the identification of the local maxima in the echo return. From a scattering perspective, this restricts the detected returns to a$\mathrm{s}$ interfaces that are more specular and appear as a detectable peak, rather than just the strength of the leading edge.

Assessment of the snow depth retrievals in the Arctic with in situ measurements from two field programs shows that they are within $-1.8 \pm 3.4$ and $-2.2 \pm 4.6 \mathrm{~cm}$ of those obtained with magna probes (see Kwok et al., 2017). Additionally, the bandwidth of the radar system (or range resolution) imposes a lower bound on the resolvable snow depth to $\sim 8 \mathrm{~cm}$.

\subsection{CryoSat-2 freeboard}

Along-track CS-2 freeboards are those from Kwok and Cunningham (2015). The reader is referred to Kwok and Cunningham (2015) for a more detailed description of the retrieval procedures and quality of these fields. As there are no direct freeboard estimates, comparisons to available ice thickness measurements provide an indirect measure of quality: freeboard is approximately $\sim$ one-ninth of ice thickness. The assessed differences between CS-2 and various thickness measurements are $0.06 \pm 0.29 \mathrm{~m}$ (ice draft from moorings), $0.07 \pm 0.44 \mathrm{~m}$ (submarine ice draft), $0.12 \pm 0.82 \mathrm{~m}$ (airborne electromagnetic profiles), and $-0.16 \pm 0.87 \mathrm{~m}$ (Operation IceBridge).

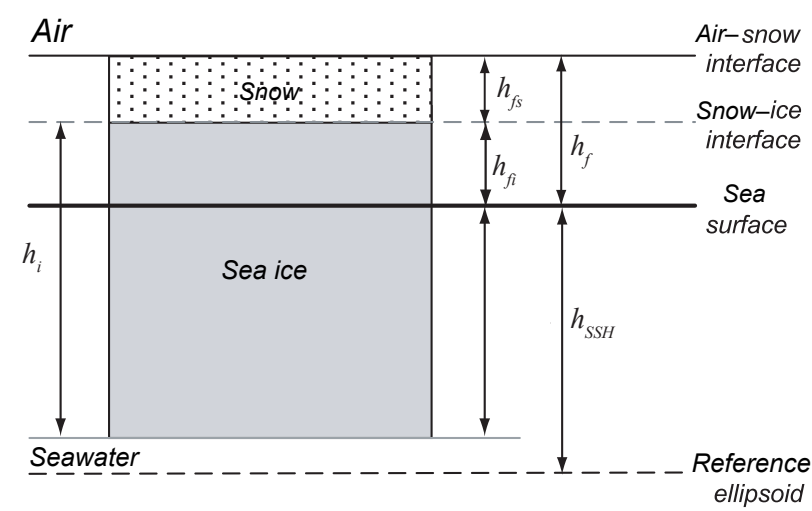

Figure 1. Relationship between the different height quantities defined in the text.

\section{Derived estimates of freeboard, snow depth, and thickness}

In this section, we outline different ways by which one can derive freeboard, snow depth, and thickness from the three retrieved quantities described in Sect. 2 (two from OIB and one from CS-2). The three quantities are (1) the total freeboard (i.e., snow+ice) from the ATM lidar $\left(h_{\mathrm{f}}^{\mathrm{ATM}}\right)$, (2) snow depth from the snow radar $\left(h_{\mathrm{fs}}^{\mathrm{SR}}\right)$, and (3) the radar freeboard $\left(h_{\mathrm{fi}}^{\mathrm{CS} 2}\right)$ from CS-2. Here, we define derived versus retrieved quantities: derived estimates, referred to in the balance of this paper and this section, are quantities calculated from the retrieved quantities. The significance of these derived estimates is discussed. In Sect. 5, we examine the differences between the retrieved and derived freeboards, snow depths, and their relative impact on thickness calculations.

\subsection{Snow depth from differences in lidar and radar freeboards}

For a simple layered system in Fig. 1, snow depth can be estimated as the difference between the retrieved ATM $\left(h_{\mathrm{f}}^{\text {ATM }}\right)$ and CS-2 $\left(h_{\mathrm{fi}}^{\mathrm{CS} 2}\right)$ freeboards (Kwok and Markus, 2017):

$\widetilde{h}_{\mathrm{fs}}=\frac{\left(h_{\mathrm{f}}^{\mathrm{ATM}}-h_{\mathrm{fi}}^{\mathrm{CS} 2}\right)}{\eta_{\mathrm{s}}}$,

where $\eta_{\mathrm{s}}=c / c_{\mathrm{s}}\left(\rho_{\mathrm{s}}\right)$ and $c / c_{\mathrm{s}}\left(\rho_{\mathrm{s}}\right)=\left(1+0.51 \rho_{\mathrm{s}}\right)^{1.5}$. The superscript "tilde" denotes a derived estimate calculated from retrieved quantities (as defined above). The adjustment (scaling by $\frac{1}{\eta_{\mathrm{s}}}$ ) compensates for the reduced propagation speed of the radar wave $\left(c_{\mathrm{s}}\right)$ in a snow layer with bulk density $\rho_{\mathrm{s}}$.

Comparison of the derived $\left(\widetilde{h}_{\mathrm{fs}}\right)$ with the retrieved snow depth $\left(h_{\mathrm{fs}}^{\mathrm{SR}}\right)$ tells us how well we can estimate snow depths using the differences between lidar $\left(h_{\mathrm{f}}^{\mathrm{ATM}}\right)$ and radar freeboards $\left(h_{\mathrm{fi}}^{\mathrm{CS} 2}\right)$ in the absence of a snow radar. This is of particular interest since near-coincident observations of freeboards from CS-2 (a radar altimeter) and IS-2 are potentially 
useful for providing large-scale estimates of snow depth (Kwok and Markus, 2017).

\subsection{Total and ice freeboards}

The total freeboard $\left(\widetilde{h}_{\mathrm{f}}\right)$ can be derived by combining the retrieved CS-2 freeboard $\left(h_{\mathrm{fi}}^{\mathrm{CS} 2}\right)$ with retrieved snow depth $\left(h_{\mathrm{fs}}^{\mathrm{SR}}\right)$ or with an estimate of the snow depth from differencing the lidar and radar freeboards $\left(\widetilde{h}_{\mathrm{fs}}\right.$ in Eq. 1).

$\tilde{h}_{\mathrm{f}}=h_{\mathrm{fi}}^{\mathrm{CS} 2}+\eta_{\mathrm{s}} h_{\mathrm{fs}}^{\mathrm{SR}}$

$\widetilde{h}_{\mathrm{f}}^{\prime}=h_{\mathrm{fi}}^{\mathrm{CS} 2}+\eta_{\mathrm{s}} \widetilde{h}_{\mathrm{fs}}$

The prime next to a variable (e.g., $\widetilde{h}^{\prime}$ ) indicates that the estimate, $\widetilde{h}$, is based on snow depth computed by differencing ATM and CS-2 freeboards (i.e., $\widetilde{h}_{\mathrm{fs}}$ ) instead of the retrieved value from the snow radar; this notation allows us to identify the quantities that are calculated using a combination of derived and retrieved quantities, rather than just retrieved quantities. By comparing these derived freeboards with $h_{\mathrm{f}}^{\mathrm{ATM}}$, the quality of the derived estimate can be assessed.

Similarly, the ice freeboards $\left(h_{\mathrm{fi}}\right.$, i.e., the height of the snow-ice interface above the local sea surface) can be derived as follows:

$\tilde{h}_{\mathrm{fi}}=h_{\mathrm{fi}}^{\mathrm{CS} 2}+h_{\mathrm{fs}}^{\mathrm{SR}}\left(\eta_{\mathrm{s}}-1\right)$,

${\tilde{h^{\prime}}}_{\mathrm{fi}}=h_{\mathrm{fi}}^{\mathrm{CS} 2}+\widetilde{h}_{\mathrm{fs}}\left(\eta_{\mathrm{s}}-1\right)$.

As above, a primed variable (e.g., $\left.\widetilde{h}^{\prime}\right)$ is one that is based on snow depth computed by differencing ATM and CS-2 freeboards (i.e., $\widetilde{h}_{\mathrm{fs}}$ ).

The expected CS-2 or radar freeboard $\left(\widetilde{h}_{\mathrm{fi}}^{\mathrm{CS} 2}\right)$ is calculated from OIB snow depth $\left(h_{\mathrm{fs}}^{\mathrm{SR}}\right)$ and total freeboard $\left(h_{\mathrm{f}}^{\mathrm{ATM}}\right)$ as

$\widetilde{h}_{\mathrm{fi}}^{\mathrm{CS} 2}=h_{\mathrm{f}}^{\mathrm{ATM}}-\eta_{\mathrm{s}} h_{\mathrm{fs}}^{\mathrm{SR}}$.

This is of interest because the comparison of derived radar freeboard $\left(\widetilde{h}_{\mathrm{f}}^{\mathrm{CS} 2}\right)$ from the OIB data with the retrieved radar freeboard $\left(h_{\mathrm{fi}}^{\mathrm{CS} 2}\right)$ may provide insights into the penetration of the radar wave into the snow layer. If the radar returns originate above the snow-ice interface due to brine or layering in the snow volume (discussed later), this will have the effect of increasing the retrieved radar freeboard (i.e., $h_{\mathrm{fi}}^{\mathrm{CS} 2}>\widetilde{h}_{\mathrm{fi}}^{\mathrm{CS} 2}$ ) or lowering the derived snow depth $\left(\widetilde{h}_{\mathrm{fs}}\right)$. The consequence is an overestimation of total and ice freeboards $\left(\widetilde{h}_{\mathrm{f}}, \widetilde{h}_{\mathrm{f}}^{\prime}, \widetilde{h}_{\mathrm{fi}}, \widetilde{h}_{\mathrm{fi}}^{\prime}\right.$ in the above equations) and therefore the sea ice thickness.

\subsection{Sea ice thickness}

Assuming hydrostatic equilibrium, sea ice thickness $\left(h_{\mathrm{i}}\right)$ from total $\left(h_{\mathrm{f}}\right)$ or ice freeboards $\left(h_{\mathrm{fi}}\right)$, with a snow layer of thickness $h_{\mathrm{fs}}$, can be calculated as follows (see geometry in Fig. 1).

$$
\begin{aligned}
& h_{\mathrm{i}}^{\text {lidar }}\left(h_{\mathrm{f}}, h_{\mathrm{fs}}\right)=\left(\frac{\rho_{\mathrm{w}}}{\rho_{\mathrm{w}}-\rho_{\mathrm{i}}}\right) h_{\mathrm{f}}-\left(\frac{\rho_{\mathrm{s}}+\rho_{\mathrm{w}}}{\rho_{\mathrm{w}}-\rho_{\mathrm{i}}}\right) h_{\mathrm{fs}}(\text { lidar }) \\
& h_{\mathrm{i}}^{\text {radar }}\left(h_{\mathrm{fi}}, h_{\mathrm{fs}}\right)=\left(\frac{\rho_{\mathrm{w}}}{\rho_{\mathrm{w}}-\rho_{\mathrm{i}}}\right) h_{\mathrm{f}}+\left(\frac{\rho_{\mathrm{s}}}{\rho_{\mathrm{w}}-\rho_{\mathrm{i}}}\right) h_{\mathrm{fs}}(\text { radar })
\end{aligned}
$$

$\rho_{\mathrm{s}}, \rho_{\mathrm{W}}$, and $\rho_{\mathrm{i}}$ are the bulk densities of snow, water, and ice, respectively. These equations are written slightly differently to show their explicit dependence on the lidar and radar observables: $h_{\mathrm{f}}$ and $h_{\mathrm{fi}}$.

With the retrieved and derived estimates of freeboard and snow depth from above, sea ice thickness can be calculated in six different ways using a combination of retrieved and derived quantities: $\quad h_{\mathrm{i}}^{\text {lidar }}\left(h_{\mathrm{f}}^{\mathrm{ATM}}, h_{\mathrm{fs}}^{\mathrm{SR}}\right), \quad h_{\mathrm{j}}^{\text {lidar }}\left(h_{\mathrm{f}}^{\mathrm{ATM}}, \widetilde{h}_{\mathrm{fs}}\right)$, $h_{\mathrm{i}}^{\text {radar }}\left(\widetilde{h}_{\mathrm{fi}}, \widetilde{f}_{\mathrm{fs}}^{\mathrm{SR}}\right), \quad h_{\mathrm{i}}^{\text {radar }}\left(\widetilde{h}_{\mathrm{fi}}, \widetilde{h}_{\mathrm{fs}}\right), \quad h_{\mathrm{i}}^{\text {radar }}\left(\widetilde{h}_{\mathrm{fi}}^{\prime}, h_{\mathrm{fs}}^{\mathrm{SR}}\right), \quad$ and $h_{\mathrm{i}}^{\text {radar }}\left(\widetilde{h}_{\mathrm{fi}}^{\prime}, \widetilde{h}_{\mathrm{fs}}\right)$. For the data set considered here, the best estimates of thickness are those using only OIB measurements, i.e., $h_{\mathrm{i}}^{\text {lidar }}\left(h_{\mathrm{f}}^{\mathrm{ATM}}, h_{\mathrm{fs}}^{\mathrm{SR}}\right)$. The third through the fifth thickness estimates (i.e., $h_{\mathrm{i}}^{\text {radar }}\left(\widetilde{h}_{\mathrm{fi}}, h_{\mathrm{fs}}^{\mathrm{SR}}\right), h_{\mathrm{i}}^{\text {radar }}\left(\widetilde{h}_{\mathrm{fi}}, \widetilde{h}_{\mathrm{fs}}\right)$, and $\left.h_{\mathrm{i}}^{\text {radar }}\left(\widetilde{h}_{\mathrm{fi}}^{\prime}, h_{\mathrm{fs}}^{\mathrm{SR}}\right)\right)$ depend on all three retrieved variables, while the other three depend only on two. If snow depths from the snow radar were not available, then the sea ice thickness can be estimated using $h_{\mathrm{i}}^{\text {lidar }}\left(h_{\mathrm{f}}^{\mathrm{ATM}}, \widetilde{h}_{\mathrm{fs}}\right)=h_{\mathrm{i}}^{\text {radar }}\left(\widetilde{h}_{\mathrm{fi}}^{\prime}, \widetilde{h}_{\mathrm{fs}}\right)$. As mentioned above, this is of particular interest if we were able to obtain near-coincident observations from a radar altimeter (e.g., CS-2) and a laser altimeter for derivation of $\widetilde{h}_{\mathrm{fs}}$, which is a possibility after the launch of IS-2.

\section{Weddell Sea: freeboard, snow depth, and ice thickness from OIB}

In this section, we examine the repeat surveys of an OIB transect of the Weddell Sea ice cover: twice in 2011 and once in 2014 and 2016. All four flights were flown in October. These OIB acquisitions represent the first large-scale airborne surveys of freeboard and snow depth of the Weddell Sea ice cover. The $\sim 3700 \mathrm{~km}$ flight track starts at a point just east of the northern tip of the Antarctic Peninsula (see Fig. 2). From there, the eastbound leg (A to B) crosses the Weddell Sea $(\sim 1500 \mathrm{~km})$ to Cape Norvegia. The second leg (B to C) heads southwest, hugging the coast before turning west, south of the Brunt Ice Shelf, for the westbound or return crossing ( $\mathrm{C}$ to $\mathrm{D}$ ). The track ends just south of James Ross Island in the western Weddell Sea. The scientific objective of this OIB loop was to sample the east-west gradient in Weddell Sea ice thickness in the outbound and return legs.

A detailed analysis of the consistency in snow depth distributions in the two 2011 repeat tracks can be found in Kwok and Maksym (2014). Here, we first discuss the spatial and interannual variability of freeboard and snow depth from the ATM lidar and snow radar and then the ice thickness derived from these retrieved quantities (Fig. 2). 

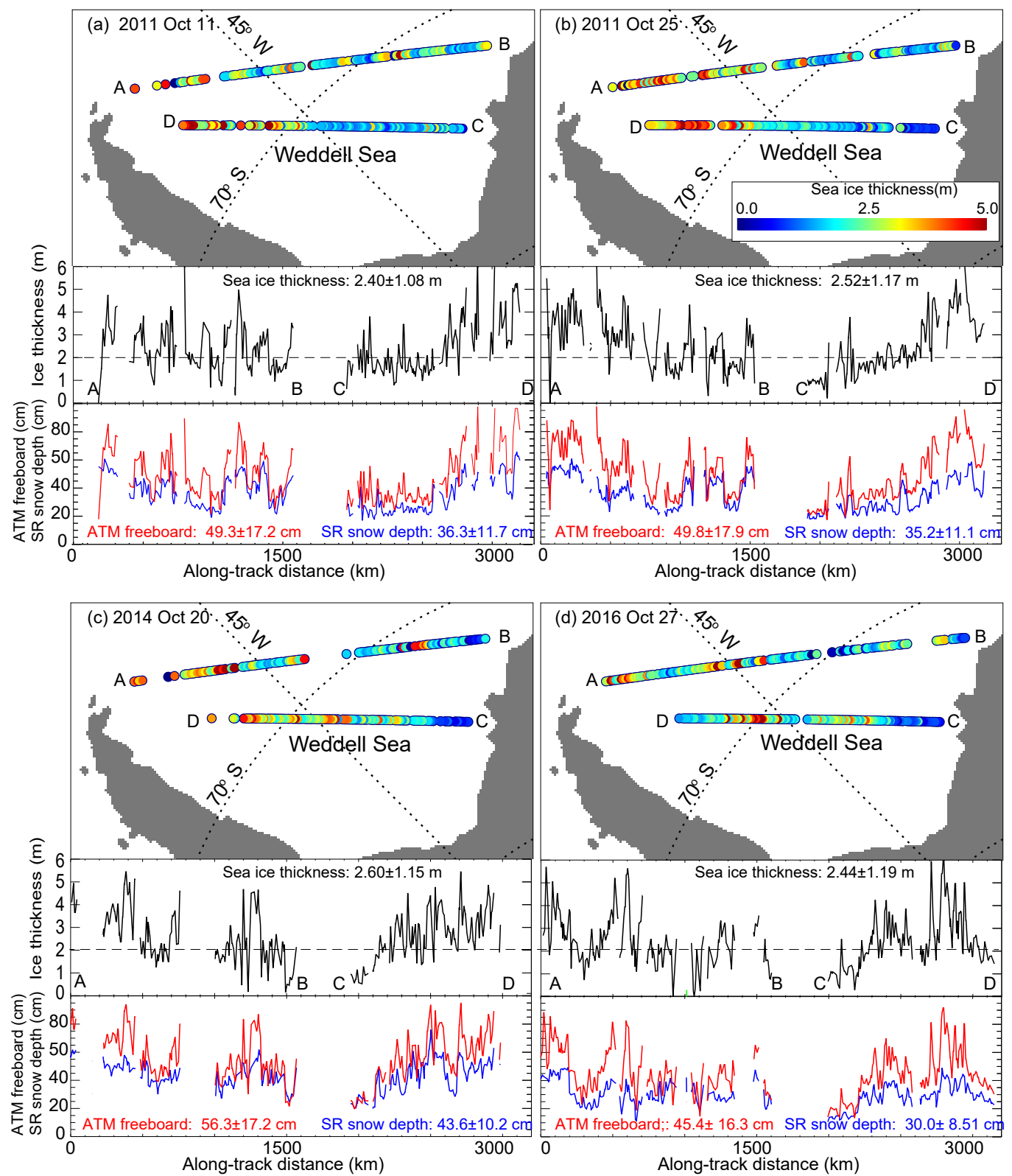

Figure 2. Repeat surveys of the Weddell Sea loop flight line in 2011, 2014, and 2016. (a) 11 October 2011. (b) 25 October 2011. (c) 20 October 2014. (d) 27 October 2016. For each flight track, we show the spatial distribution of ice thickness (top panel) and its along-track profile (middle panel) and the total freeboard and snow depth from the ATM lidar and snow radar on Operation IceBridge (bottom panel). Samples are $12.5 \mathrm{~km}$ averages.

\subsection{Freeboard and snow depth}

Even though the variability is quite high, for all three years the snow depths and total freeboards (Table 1 and Fig. 2) are generally higher in the western Weddell Sea (west of $45^{\circ} \mathrm{W}$ ). As a reminder, snow depth is the retrieved parameter from the snow radar $\left(h_{\mathrm{fs}}^{\mathrm{SR}}\right)$ and total freeboard is from the ATM lidar $\left(h_{\mathrm{f}}^{\mathrm{ATM}}\right)$. This ice cover then transitions into a region of thinner snow and freeboard in the eastern Weddell (at $\sim 1300 \mathrm{~km}$ along the track). In the westbound legs, the large-scale trends are reversed; i.e., the snow and freeboard become thicker as the flight track approaches the western Weddell and the coast of the Antarctic Peninsula. For the three years, this east-west gradient is seen in both the outbound legs (A to B) in the north and the return legs (C to D) farther to the south.

Averaged over the entire transect, the snow depths (in $\mathrm{cm}$ ) are $36.3 \pm 11.7$ (11 October 2011), 35.2 \pm 11.0 (25 October 2011), $43.6 \pm 10.2$ (20 October 2014), and $30.0 \pm 8.51$ 
Table 1. (a) Mean total freeboards $\left(h_{\mathrm{f}}^{\mathrm{ATM}}, \widetilde{h}_{\mathrm{f}}\right)$ and ice freeboards $\left(\widetilde{h}_{\mathrm{fi}}, \widetilde{h}_{\mathrm{fi}}\right)$ along the Weddell Sea transect in 2011, 2014, and 2016 (retrieved quantities from OIB and CS-2 only are in bold, the other quantities are derived). (b) Mean radar freeboard $\left(h_{\mathrm{fi}}^{\mathrm{CS} 2}, \widetilde{h}_{\mathrm{fi}}^{\mathrm{CS} 2}\right)$ and snow depth $\left(h_{\mathrm{fs}}^{\mathrm{SR}}, \widetilde{h}_{\mathrm{fs}}\right)$ in 2011,2014 , and 2016.

\begin{tabular}{lllll}
\hline (a) Centimeters & $h_{\mathrm{f}}^{\text {ATM }}$ & $\widetilde{h}_{\mathrm{f}}$ & $\widetilde{h}_{\mathrm{fi}}$ & ${\widetilde{h^{\prime}}}_{\mathrm{fi}}$ \\
\hline 2011 (12 and 25 October) & $\mathbf{4 9 . 3} \pm \mathbf{1 7 . 2}$ & $56.3 \pm 20.3$ & $19.9 \pm 10.1$ & $18.7 \pm 8.89$ \\
& $\mathbf{4 9 . 8} \pm \mathbf{1 7 . 9}$ & $54.7 \pm 19.3$ & $19.4 \pm 9.72$ & $18.5 \pm 8.94$ \\
2014 (20 October) & $\mathbf{5 6 . 3} \pm \mathbf{1 7 . 2}$ & $67.0 \pm 16.6$ & $23.4 \pm 7.70$ & $21.5 \pm 7.30$ \\
2016 (27 October) & $\mathbf{4 5 . 4} \pm \mathbf{1 6 . 3}$ & $47.3 \pm 13.3$ & $17.3 \pm 6.67$ & $16.9 \pm 6.67$ \\
\hline (b) Centimeters & $h_{\mathrm{fi}}^{\text {CS2 }}$ & $\widetilde{h}_{\mathrm{fi}}^{\mathrm{CS} 2}$ & $h_{\mathrm{fs}}^{\mathrm{SR}}$ & $\widetilde{h}_{\mathrm{fs}}$ \\
\hline 2011 (12 and 25 October) & $\mathbf{1 1 . 9} \pm \mathbf{8 . 4 0}$ & $6.00 \pm 7.21$ & $\mathbf{3 6 . 3} \pm \mathbf{1 1 . 7}$ & $30.6 \pm 12.1$ \\
& $\mathbf{1 1 . 7} \pm \mathbf{8 . 1 0}$ & $7.66 \pm 7.73$ & $\mathbf{3 5 . 2} \pm \mathbf{1 1 . 0}$ & $31.1 \pm 12.1$ \\
2014 (20 October) & $\mathbf{1 3 . 8} \pm \mathbf{6 . 2 8}$ & $5.39 \pm 6.48$ & $\mathbf{4 3 . 6} \pm \mathbf{1 0 . 2}$ & $34.9 \pm 12.0$ \\
2016 (27 October) & $\mathbf{1 0 . 7} \pm \mathbf{5 . 9 1}$ & $9.52 \pm 8.89$ & $\mathbf{3 0 . 0} \pm \mathbf{8 . 5 1}$ & $28.3 \pm 12.1$ \\
\hline
\end{tabular}

(27 October 2016; see Table 1), and the total freeboards (in $\mathrm{cm})$ are 49.3 \pm 17.2 (11 October 2011), 49.8 \pm 17.9 (25 October 2011), $56.3 \pm 17.2$ (20 October 2014), and $45.4 \pm 16.3 \mathrm{~cm}$ (27 October 2016). Although the data set covers only three years, it provides some indication of interannual variability. It is of interest to note the correspondence between higher snow depths and freeboards in 2014 and lower snow depths and freeboards in 2016. In all but a few samples (two to three $12.5 \mathrm{~km}$ samples) total freeboards are higher than snow depths (on average $\sim 13 \mathrm{~cm}$ ), suggesting limited areas where the consequence of snow loading leads to zero or near-zero ice freeboard.

The $12.5 \mathrm{~km}$ averages of snow depth shown here range from $\sim 50 \mathrm{~cm}$ near the Antarctic Peninsula to $\sim 10 \mathrm{~cm}$ in the eastern Weddell. Consistent with that reported in Kwok and Maksym (2014; in which they reported extremes in $4 \mathrm{~km}$ averages), the snow depths in all three years are generally higher than the vast majority of those reported from in situ data (Massom et al., 2001). As noted in Kwok and Maksym (2014), field observations of snow depth from two sources - underway shipboard observations and mechanical drilling profiles - favor sampling of the thinner end of the snow depth distribution due to physical and logistical constraints; thus, these sample populations may not be representative of regional statistics. Furthermore, the sea ice cover sampled by the OIB tracks has rarely been surveyed this late in the season (i.e., October), in part because of restricted ship accessibility to these areas with thicker ice and snow. By the time of these OIB surveys, the ice cover will have experienced the full season of growth, deformation, and snow accumulation. We attribute the differences seen here, in large part, to spatial sampling constraints inherent in available field measurements and to the lack of observations during spring in much of the Weddell Sea.

For all three years, the snow depth retrievals suggest that much of the region in the interior pack in spring, particularly near the Antarctic Peninsula, has much deeper snow (and thicker ice; see below) than has typically been described elsewhere. The regions of heavy deformation and multiyear ice in the western Weddell Sea have rarely been sampled (particularly in spring), and these ice types are well known to possess deep snow covers. Potentially, due to the resolution limitations of the snow radar (lower bound on the resolvable snow depth is $\sim 8 \mathrm{~cm}$ ), the areas of thin snow and ice are undersampled by our retrieval process, but this does not preclude the fact that areas of much thicker snow are seen in the data and therefore sampling for obtaining regional statistics remains an issue.

\subsection{Sea ice thickness}

Averaged over this transect, ice thickness ranges between $2.40 \pm 1.07$ and $2.51 \pm 1.16$ (October 2011) and $2.60 \pm 1.15 \mathrm{~m}$ (October 2014) and 2.44 $\pm 1.18 \mathrm{~m}$ (October 2016; Table 2 and Fig. 2), strikingly similar for the three years. As with the east-west gradient in snow depth and freeboard, the thicker sea ice is in the more deformed ice cover in the western Weddell Sea. Another point of note is that even though there is a $13 \mathrm{~cm}$ difference in the average snow depth between 2014 and 2016, the difference in thickness between the two years is only $0.16 \mathrm{~m}$ because the difference in total freeboard is only $11 \mathrm{~cm}$, giving a small overall thickness change. The $12.5 \mathrm{~km}$ averages of ice thickness shown here range from $\sim 5 \mathrm{~m}$ near the Antarctic Peninsula to $\sim 1 \mathrm{~m}$ in the eastern Weddell.

Recent surveys of ice draft in the northwest Weddell Sea using autonomous underwater vehicles (Williams et al., 2015) report highly variable ice drafts in a deformed ice cover with a mean draft of $2.40 \pm 1.68 \mathrm{~m}$ and a maximum draft exceeding $14 \mathrm{~m}$. The authors note that their measurements in the Weddell Sea are much higher than those reported by most drilling (mean / SD draft: $1.05 \pm 0.4 \mathrm{~m}$ ) and ship-based measurements (mean / SD draft: $1.01 \pm 0.5 \mathrm{~m}$; see Table 1 in Williams et al., 2015). Our thickness averages also suggest, on an even broader spatial and temporal scale, a 
Table 2. Mean sea ice thickness along the Weddell Sea loop from retrieved and derived freeboards and snow depths (2011, 2014, and 2016).

\begin{tabular}{lll|ll|ll}
\hline & \multicolumn{2}{c}{$2011(12$ and 25 October $)$} & \multicolumn{2}{c}{2014 (20 October) } & \multicolumn{2}{c}{2016 (27 October) } \\
\hline Meters & $h_{\mathrm{fs}}^{\mathrm{SR}}$ & $\tilde{h}_{\mathrm{fs}}$ & $h_{\mathrm{fs}}^{\mathrm{SR}}$ & $\tilde{h}_{\mathrm{fs}}$ & $h_{\mathrm{fs}}^{\mathrm{SR}}$ & $\tilde{h}_{\mathrm{fs}}$ \\
\hline$h_{\mathrm{f}}^{\mathrm{ATM}}$ & $\mathbf{2 . 4 0} \pm \mathbf{1 . 0 7}$ & $2.77 \pm 1.06$ & $\mathbf{2 . 6 0} \pm \mathbf{1 . 1 5}$ & $3.17 \pm 0.97$ & $\mathbf{2 . 4 4} \pm \mathbf{1 . 1 8}$ & $2.54 \pm 0.90$ \\
& $\mathbf{2 . 5 1} \pm \mathbf{1 . 1 6}$ & $2.78 \pm 1.10$ & & & & \\
\hline$\tilde{h}_{\mathrm{fi}}$ & $3.07 \pm 1.29$ & $2.89 \pm 1.13$ & $3.62 \pm 1.00$ & $3.36 \pm 0.97$ & $2.62 \pm 0.83$ & $2.57 \pm 0.87$ \\
& $2.99 \pm 1.23$ & $2.87 \pm 1.14$ & & & & \\
\hline$\widetilde{h}_{\mathrm{fi}}^{\prime}$ & $3.07 \pm 1.17$ & $2.77 \pm 1.06$ & $3.62 \pm 0.97$ & $3.17 \pm 0.97$ & $2.62 \pm 0.84$ & $2.54 \pm 0.90$ \\
& $2.99 \pm 1.16$ & $2.78 \pm 1.10$ & & & & \\
\hline
\end{tabular}

Notes: (1) $h_{\mathrm{i}}^{\text {lidar }}\left(h_{\mathrm{f}}^{\mathrm{ATM}}, \widetilde{h}_{\mathrm{fs}}\right)=h_{\mathrm{j}}^{\mathrm{radar}}\left(\widetilde{h}_{\mathrm{f}}^{\prime}, \widetilde{h}_{\mathrm{fs}}\right)$. (2) Thickness estimates using only OIB retrievals are in bold. (3) Thickness estimates using only OIB ATM and CS-2 freeboards (i.e., not using snow depths from the OIB snow radar) are in italics.

thicker and more highly variable Weddell Sea ice cover than that inferred from drilling and ship-based measurements. Again, this highlights the potential limitations of shipboard observations and drilling as they favor sampling of the thinner end of snow and thickness distributions due to physical and logistical constraints.

\subsection{Sampling of the snow depth distribution and ice thickness}

As mentioned in Sect. 2, the bandwidth of the radar system (or range resolution) imposes a lower limit on the resolvable snow depth to $\sim 8-10 \mathrm{~cm}$. Further, over fairly rough surfaces, the retrievals tend to be discarded as unreliable (Kwok et al., 2011). These omissions at the two extremes cause an incomplete sampling of the snow depth distribution, and thus the question arises as to how these shortcomings in sampling affect the statistics of the snow depth distribution and the calculated ice thickness when total freeboards are used. That is, how representative are the regional averages discussed above? One way to address the potential sampling biases was employed by Kwok and Maksym (2014): they used tabulated relationships between OIB snow depth and total freeboard (i.e., $\left.h_{\mathrm{fs}}^{\mathrm{SR}}=f\left(h_{\mathrm{f}}^{\mathrm{ATM}}\right)\right)$ to estimate snow depths at lidar samples (i.e., total freeboard) for which there were no retrievals. We follow this approach: we fill the samples with no snow depth retrievals and then compare the snow depth distributions and the calculated thickness estimates before and after filling the samples. The results are shown in Fig. 3.

For the repeat Weddell tracks, the averaged snow depths (after filling) are lower between $4.0 \mathrm{~cm}$ (in 2011) and $6.0 \mathrm{~cm}$ (in 2014), largely due to the undersampling of thin snow, which is a limitation due to the resolution of the snow radar. The resulting ice thickness estimates are actually higher (between $0.09 \mathrm{~m}$ in 2016 and $0.37 \mathrm{~m}$ in 2014). This is somewhat counterintuitive, as reduced snow loading should imply lower ice thickness for a fixed ice freeboard. Here, however, we calculate thickness with averaged along-track total freeboard and there may be missing snow depth retrievals in the corresponding along-track snow depth averages. As the ice freeboard is the difference between total freeboard and snow depth, the ice freeboard becomes higher when the snow depth is lowered (due to more complete sampling of the thin end of the snow depth distribution), thereby increasing the ice thickness estimates.

In this case, the results from this simple assessment suggest that, in our current calculations, the spatially averaged snow depths may be overestimated, while ice thickness may be underestimated if we did not account for the thin end of the snow depth distribution.

\section{Estimates of snow depth and ice thickness using lidar and radar freeboards}

In this section, we address the use of ATM and CS-2 freeboards to estimate snow depth and ice thickness with the aim of identifying potential biases in radar freeboard and snow depth that may impact thickness estimates. First, we discuss the construction of CS-2 freeboard estimates at the ATM ground tracks. Second, we compare the retrieved CS-2 radar freeboards with those derived from OIB retrievals (lidar and snow depth). Third, we compare the derived snow depths $\left(\widetilde{h}_{\mathrm{fs}}\right)$, total freeboard $\left(\widetilde{h}_{\mathrm{f}}^{\prime}\right)$, and ice thickness with those computed using the retrieved quantities from OIB. Last, we examine the potential biases in thickness estimates if only lidar freeboards were available.

\subsection{Colocating CS-2 and ATM freeboards}

Because of the disparity in spatial resolution and the spacetime sampling of the Antarctic ice cover by the CS-2 altimeter, the OIB ATM lidar, and the snow radar, the first step of the process is to construct space-time averages with sample populations that are large enough to support the analysis undertaken here. We follow the procedure in Kwok and Markus (2017), in which CS-2 freeboards interpolated to the ATM track locations are from 30-day gridded fields $(12.5 \mathrm{~km}$ by $12.5 \mathrm{~km}$ ) centered on the day of each of the OIB flights. 
(a)
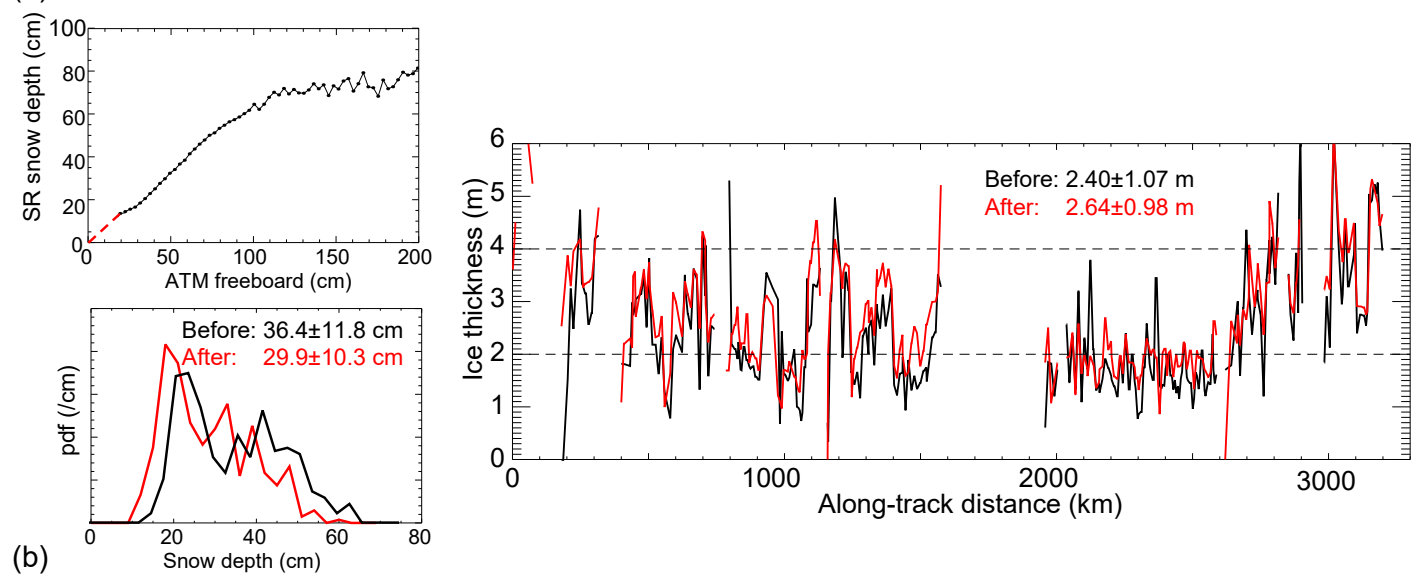

(b)
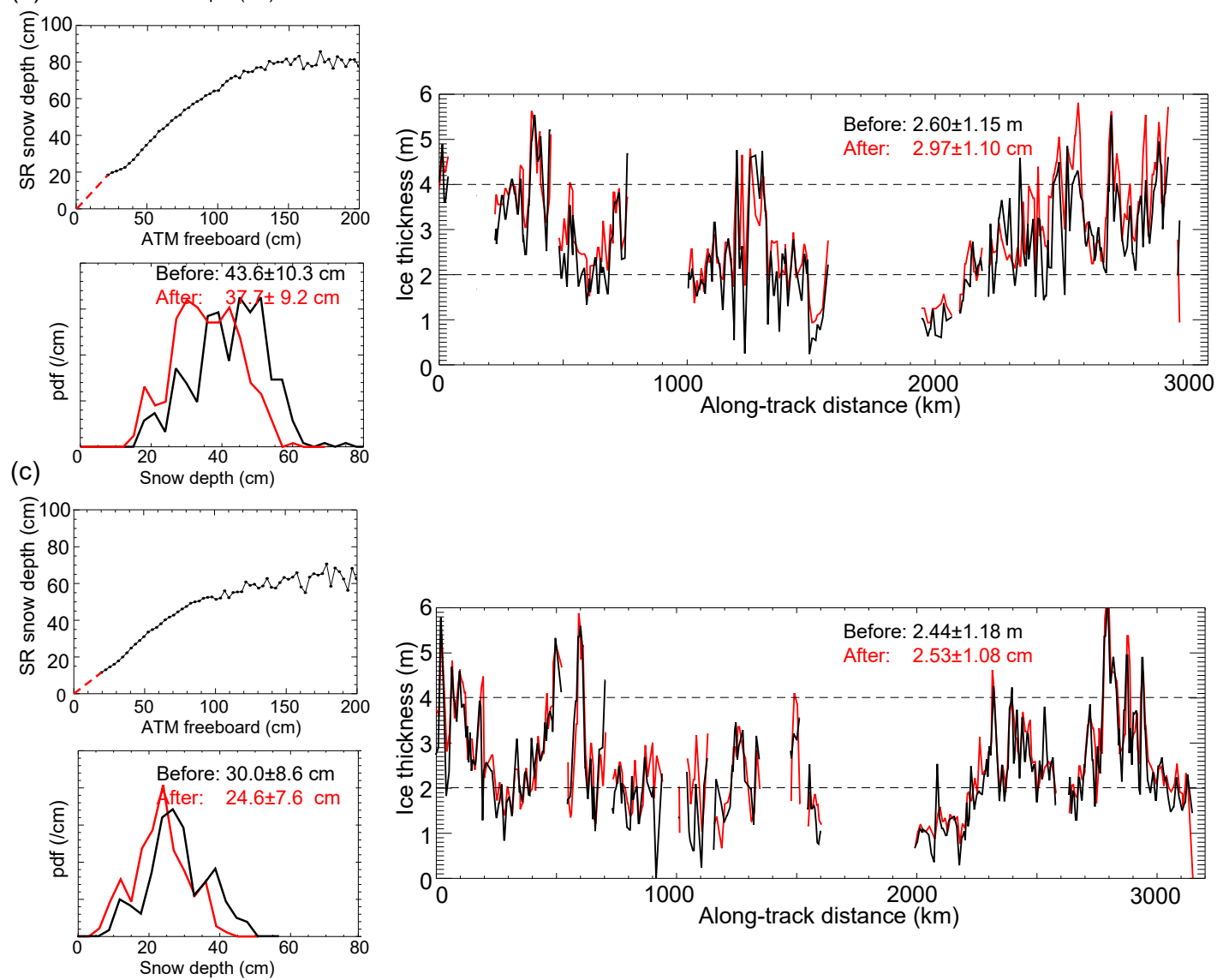

Figure 3. Sampling of snow depth distributions and thickness estimates. (a) 11 October 2011. (b) 20 October 2014 . (c) 27 October 2016. For each date, we show the relationships between snow depth and total freeboard (top left) and between the snow depth distributions (bottom left) and the thickness profiles (right) before (black) and after (red) filling the freeboard samples without snow depth retrievals. The dashed red line in the top left of each panel shows the presumed relationship between snow depth and total freeboard when snow depths are not resolved by the snow radar. 25 October 2011 is not shown here.

The choice of sampling for these comparisons is governed by limitations of the two data sets (OIB ATM and SR, CS-2). In particular, the OIB lidar data are acquired only during October and the sampling of the OIB flight lines is generally not aligned with the CS-2 ground tracks in time and space. Since the CS-2 ground tracks do not provide dense coverage of the surface, we are dependent on comparing spatial averages in the monthly CS-2 freeboard composites with the along-track freeboard averages from the OIB mission (see Fig. 4). 
(a) 2011 Oct 11
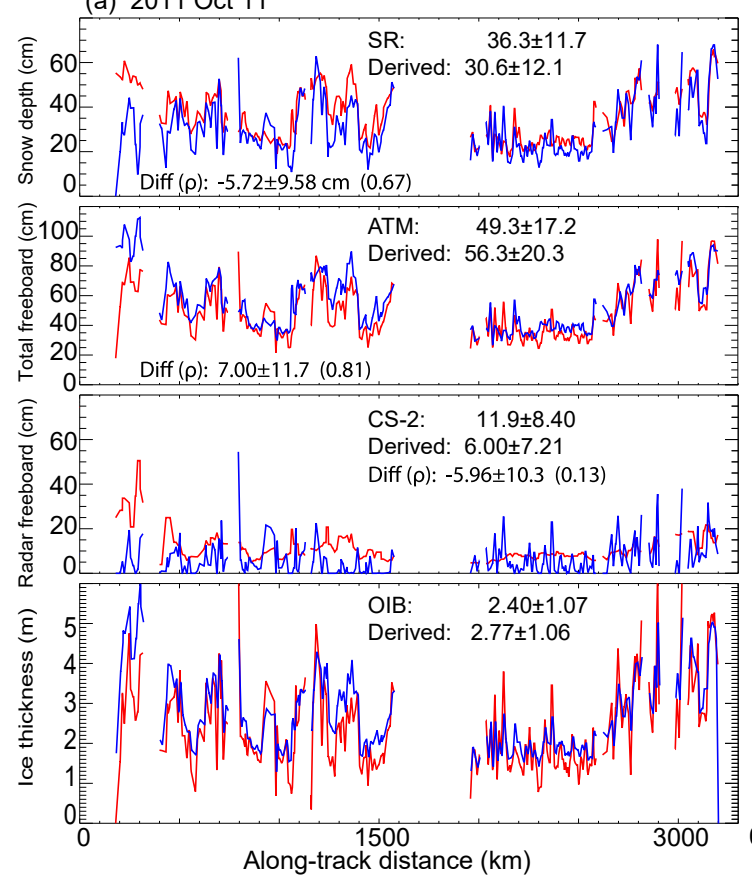

(b) 2011 Oct 25

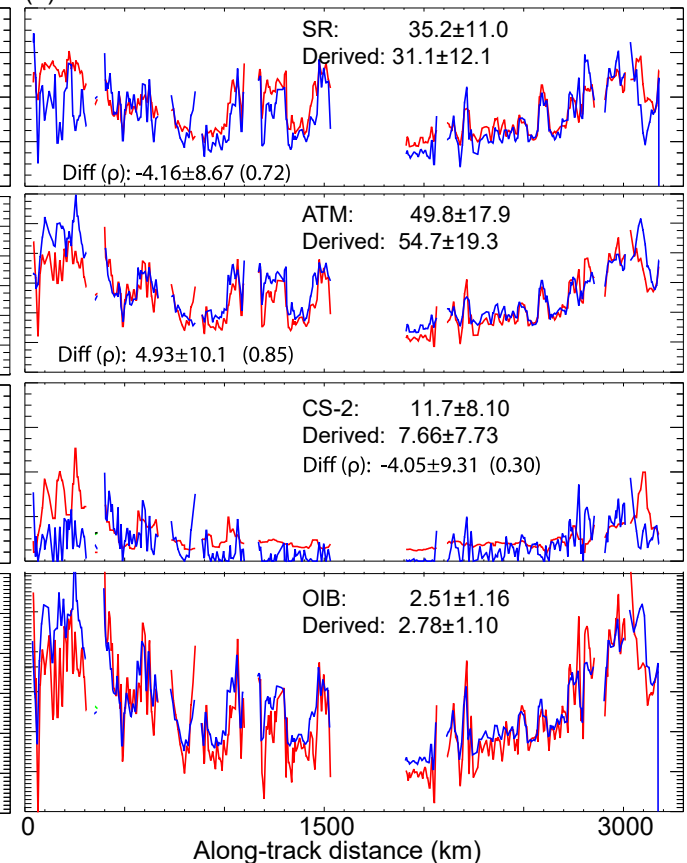

Figure 4. Comparisons of observed and derived snow depth, total freeboard, radar freeboard, and ice thickness for (a) 11 October 2011 and (b) 25 October 2011. Top row: snow depth $\left(\widetilde{h}_{\mathrm{fs}}\right.$ vs. $\left.h_{\mathrm{fs}}^{\mathrm{SR}}\right)$. Second row: total freeboard $\left(\widetilde{h}_{\mathrm{f}}^{\prime}\right.$ vs. $\left.h_{\mathrm{f}}^{\mathrm{ATM}}\right)$. Third row: ice freeboard $\left(\widetilde{h}_{\mathrm{fi}}^{\text {CS2 }}\right.$ vs. $\left.h_{\mathrm{fi}}^{\mathrm{CS} 2}\right)$. Bottom row: ice thickness $\left(h_{\mathrm{i}}^{\mathrm{radar}}\left(\widetilde{h}_{\mathrm{fi}}^{\prime}, \widetilde{h}_{\mathrm{fs}}\right)\right.$ vs. $\left.h_{\mathrm{i}}^{\text {lidar }}\left(h_{\mathrm{f}}^{\mathrm{ATM}}, h_{\mathrm{fs}}^{\mathrm{SR}}\right)\right)$. Note that $h_{\mathrm{i}}^{\text {lidar }}\left(h_{\mathrm{f}}^{\mathrm{ATM}}, \widetilde{h}_{\mathrm{fs}}\right)=h_{\mathrm{i}}^{\text {radar }}\left(\widetilde{h}_{\mathrm{fi}}^{\prime}, \widetilde{h}_{\mathrm{fs}}\right)$. Snow depths from $\mathrm{OIB}\left(h_{\mathrm{fs}}^{\mathrm{SR}}\right)$ are not used in the derived estimates. Samples are $12.5 \mathrm{~km}$ averages.

\subsection{Comparison of CS-2 freeboard estimates}

Derived radar CS-2 freeboards $\left(\widetilde{h}_{\mathrm{fi}}^{\mathrm{CS} 2}\right)$ along the transect are compared with the retrieved radar freeboards $\left(h_{\mathrm{fi}}^{\mathrm{CS} 2}\right)$ in Figs. 4 and 5. $\widetilde{h}_{\mathrm{fi}}^{\mathrm{CS} 2}$ is calculated with Eq. (6) using total freeboards from the ATM lidar $\left(h_{\mathrm{f}}^{\mathrm{ATM}}\right)$ and snow depths from the snow radar $\left(h_{\mathrm{fs}}^{\mathrm{SR}}\right)$. For the three years, mean $h_{\mathrm{fi}}^{\mathrm{CS} 2}$ ranges from $\sim 11$ to $14 \mathrm{~cm}$, while $\widetilde{h}_{\mathrm{fi}}^{\mathrm{CS} 2}$ ranges from $\sim 5$ to $9 \mathrm{~cm}$; their standard deviations (6 to $9 \mathrm{~cm}$ ) are comparable (Table 1). The CS-2 radar freeboards $\left(h_{\mathrm{fi}}^{\mathrm{CS} 2}\right)$ are consistently higher than the derived radar freeboards $\left(h_{\mathrm{fi}}^{\text {CS2 }}\right)$. Differences along individual tracks are $5.96 \pm 10.3$ and $4.05 \pm 9.31 \mathrm{~cm}$ (two flights in October 2011), $8.45 \pm 7.08 \mathrm{~cm}$ (October 2014), and $1.21 \pm 8.22 \mathrm{~cm}$ (October 2016; see also Table 3).

Equation (6) assumes that the difference between $h_{\mathrm{f}}^{\text {ATM }}$ and $h_{\mathrm{fi}}^{\mathrm{CS} 2}$ can be explained entirely by the reduced propagation speed of the radar wave in a snow layer. If the radar returns are from above the snow-ice interface due to salinity or layering in the snow volume, this will have the effect of increasing the radar freeboard (i.e., $h_{\mathrm{fi}}^{\mathrm{CS} 2}>\widetilde{h}_{\mathrm{fi}}^{\mathrm{CS} 2}$ ). While these differences may be due to ATM freeboard or snow depth retrievals, the magnitude of these differences (except for 2016) seem too high to be attributable to $h_{\mathrm{f}}^{\mathrm{ATM}}$ or $h_{\mathrm{fs}}^{\mathrm{SR}}$ (as discussed in Sect. 2), suggesting that retrieved $h_{\mathrm{fi}}^{\mathrm{CS} 2}$ may indeed be higher than the expected ice freeboard.
The agreement in the direction of the bias (i.e., $h_{\mathrm{fi}}^{\mathrm{CS} 2}>$ $\widetilde{h}_{\mathrm{fi}}^{\mathrm{CS} 2}$ ) over the three years may be fortuitous, but other evidence also points to the displacement of the scattering surface away from the snow-ice interface. In an assessment of ERS-2 radar altimetry ( $\mathrm{K}_{\mathrm{u}}$ band: also CS-2 frequency) over the Weddell Sea, Giles et al. (2008) also found that the radar freeboards from ERS are higher than expected for ice freeboards, which suggested that the radar may not be penetrating to the snow-ice interface. Field studies of $\mathrm{K}_{\mathrm{u}}$ band (CS2 frequency) penetration into the snow cover (Willatt et al., 2010) also reported that the snow-ice interface was the dominant scattering surface only for snow without morphological features or flooding. In a review article of snow on Antarctic sea ice, Massom et al. (2001) report that as a result of capillary suction of brine and flooding, high salinities (>10 psu) occur up to about $0.1 \mathrm{~m}$ in the snow column, but mainly in the basal layer 0-5 cm above the ice surface. A recent analysis by Nandan et al. (2017) indicates that saline snow above the snow-ice interface on Arctic sea ice (observed on fast ice in the Canadian Arctic Archipelago) may indeed mask the contribution of scattering of the snow-ice interface to the radar return by effectively reducing the penetration into the snow volume, hence affecting thickness estimates using radar freeboards. While the processes associated with saline snow may be different in the Southern Ocean ice cover (perhaps saline snow associated with flooding as noted by Willatt et 
(a) 2014 Oct 20

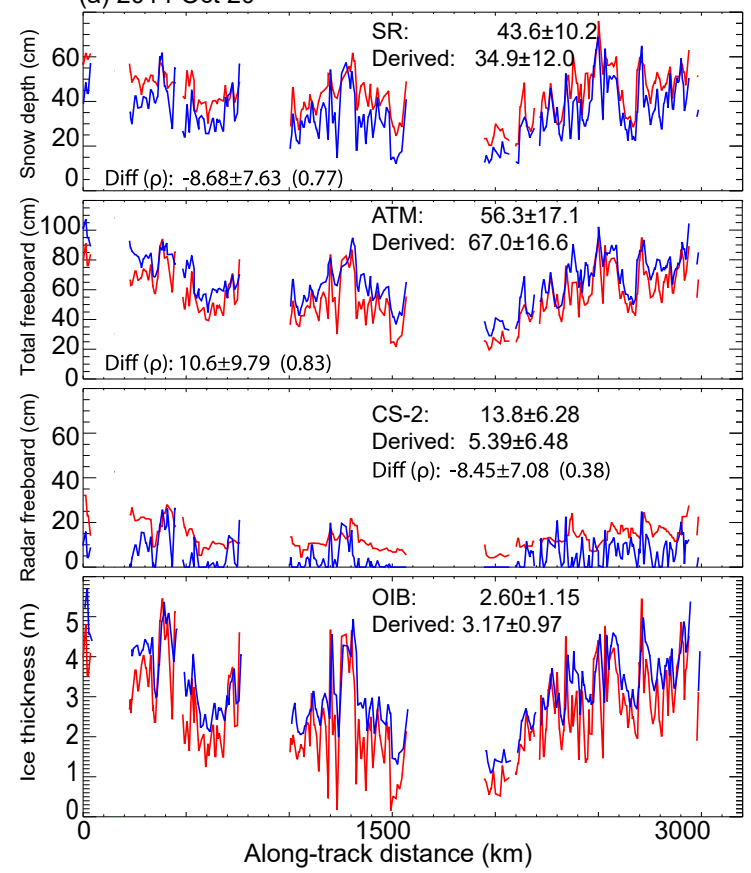

(b) 2016 Oct 27

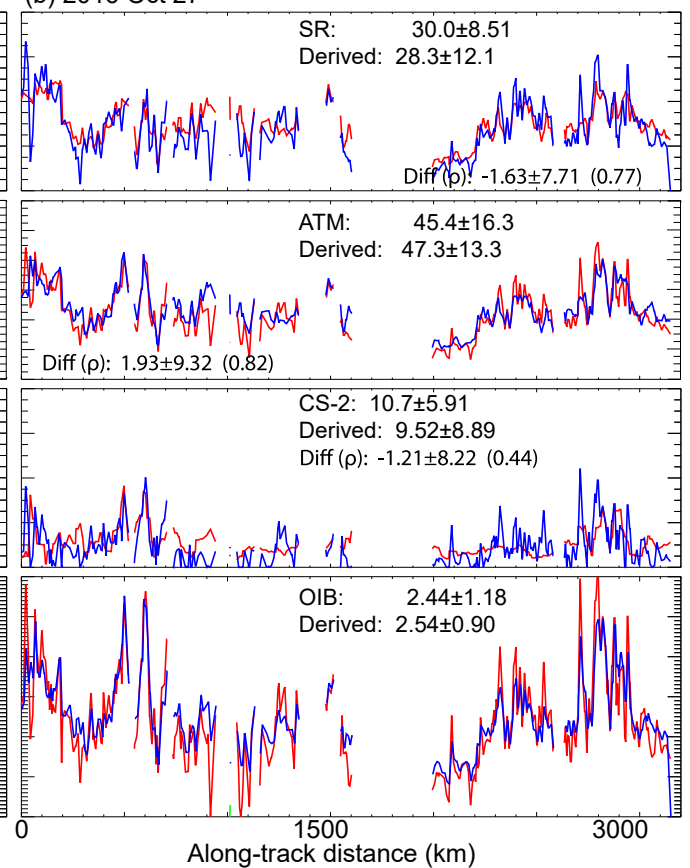

Figure 5. Same as Fig. 4 but for (a) 20 October 2014 and (b) 27 October 2016.

Table 3. Differences (mean and standard deviation) and correlation $(\rho)$ between the derived and retrieved total freeboard, snow depth, radar (CS-2) freeboard, and ice freeboard in 2011, 2014, and 2016.

\begin{tabular}{lcr|rc|cc}
\hline $\mathrm{cm} / \rho$ & 2011 (12 and 25 October) & 2014 (20 October) & \multicolumn{2}{|c}{2016 (27 October) } \\
\hline$\tilde{h}_{\mathrm{f}}$ vs. $h_{\mathrm{f}}^{\mathrm{ATM}}$ & $7.00 \pm 11.7$ & 0.81 & $10.6 \pm 9.79$ & 0.83 & $1.93 \pm 9.32$ & 0.82 \\
& $4.93 \pm 10.1$ & 0.85 & & & & \\
\hline$\widetilde{h}_{\mathrm{fs}}$ vs. $h_{\mathrm{fs}}^{\mathrm{SR}}$ & $-5.72 \pm 9.58$ & 0.67 & $-8.68 \pm 7.63$ & 0.77 & $-1.63 \pm 7.71$ & 0.77 \\
& $-4.16 \pm 8.67$ & 0.72 & & & & \\
\hline$h_{\mathrm{fi}}^{\text {CS2 }}$ vs. $\tilde{h}_{\mathrm{fi}}^{\mathrm{CS} 2}$ & $5.96 \pm 10.3$ & 0.13 & $8.45 \pm 7.08$ & 0.38 & $1.21 \pm 8.22$ & 0.44 \\
& $4.05 \pm 9.31$ & 0.30 & & & & \\
\hline$\widetilde{h}_{\mathrm{fi}}^{\prime}$ vs. $\tilde{h}_{\mathrm{fi}}$ & $-1.26 \pm 2.10$ & 0.98 & $-1.91 \pm 1.67$ & 0.97 & $-0.35 \pm 1.69$ & 0.96 \\
& $-0.91 \pm 1.90$ & 0.98 & & & & \\
\hline
\end{tabular}

al., 2010, and Massom et al., 2001), the results suggest a source of bias in the radar returns worthy of further investigation.

The consequence is an overestimation of total and ice freeboards $\left(\widetilde{h}_{\mathrm{f}}, \widetilde{h}_{\mathrm{f}}^{\prime}, \widetilde{h}_{\mathrm{fi}}, \widetilde{h}_{\mathrm{fi}}^{\prime}\right.$ in the equations above) and therefore the sea ice thickness using Eqs. (7) and (8). Over the three years, these results also suggest that the biases may be dependent on snow loading as the biases are higher in 2014 when the mean snow depth was highest (mean: $43.6 \mathrm{~cm}$ ) and the biases are lower in 2016 when the mean snow depth was lowest (mean: $\sim 30.0 \mathrm{~cm}$ ). But a more extensive data set would be required to quantify and substantiate this dependence.

\subsection{Comparison of snow depth, freeboard, and thickness estimates}

When the retrieved $h_{\mathrm{f}}^{\mathrm{CS} 2}$ values are higher than expected (see above), the derived snow depths $\left(\widetilde{h}_{\mathrm{fs}}\right)$ calculated using Eq. (1) are lower, and the derived total freeboards $\left(\widetilde{h}_{\mathrm{f}}\right)$ calculated using Eq. (2) are higher (Figs. 4 and 5, Table 3). The differences between $\widetilde{h}_{\mathrm{fs}}$ and $h_{\mathrm{fs}}^{\mathrm{SR}}$ and between $\widetilde{h}_{\mathrm{f}}$ and $h_{\mathrm{f}}^{\mathrm{ATM}}$ are shown in Table 3.

Comparison of $\tilde{h}_{\mathrm{fs}}$ with $h_{\mathrm{fs}}^{\mathrm{SR}}$ tells us how well we can estimate snow depths, in the absence of a snow radar, by differencing lidar $\left(h_{\mathrm{f}}^{\mathrm{ATM}}\right)$ and radar freeboards $\left(h_{\mathrm{fi}}^{\mathrm{CS} 2}\right)$. As mentioned earlier, this is of particular interest since nearcoincident observations of freeboards from CS-2 (a radar al- 


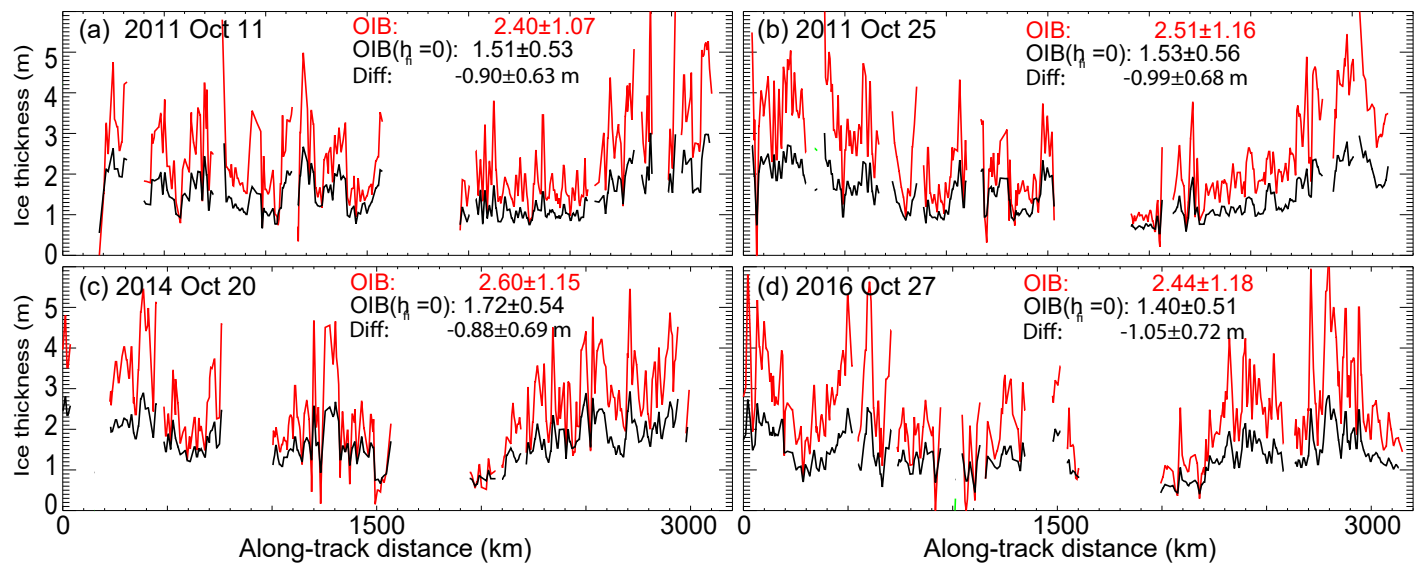

Figure 6. Estimates of ice thickness assuming zero ice freeboard (i.e., $h_{\mathrm{fi}}=0$ or $h_{\mathrm{i}}^{\text {lidar }}\left(h_{\mathrm{f}}^{\mathrm{ATM}}, h_{\mathrm{fs}}^{\mathrm{SR}}\right)$ vs. $h_{\mathrm{i}}^{\text {lidar }}\left(h_{\mathrm{f}}^{\mathrm{ATM}}, h_{\mathrm{f}}^{\mathrm{ATM}}\right)$ or $\left.h_{\mathrm{i}}^{\mathrm{radar}}\left(0, h_{\mathrm{f}}^{\mathrm{ATM}}\right)\right)$. (a) 11 October 2011. (b) 25 October 2011. (c) 20 October 2014. (d) 27 October 2016. Samples are 12.5 km averages.

timeter) and IS-2 (a lidar to be launched in late 2018) are potentially useful for providing large-scale estimates of snow depth (Kwok and Markus, 2017). The results indicate that the derived snow depth may be lower than expected, perhaps due to the processes discussed earlier.

When $h_{\mathrm{f}}^{\text {ATM }}$ and the derived $\widetilde{h}_{\mathrm{fs}}$ are used to estimate ice thickness using Eq. (7) (i.e., $\left.h_{\mathrm{i}}^{\text {lidar }}\left(h_{\mathrm{f}}^{\mathrm{ATM}}, \widetilde{h}_{\mathrm{fs}}\right)\right)$, the resulting ice cover is thicker because a larger fraction of the total freeboard is given to the higher-density sea ice than to the lower-density snow layer. For the three years, the derived transect-averaged ice thicknesses are (in meters) $2.77 \pm 1.06$ and 2.78 \pm 1.10 (October 2011), $3.17 \pm 0.97$ (October 2014), and 2.54 \pm 0.90 (October 2016; Table 2 and Figs. 4 and 5). This is between 0.1 and $0.6 \mathrm{~m}$ thicker than those thicknesses discussed in Sect. 3: $2.40 \pm 1.07$ and $2.51 \pm 1.16$ (October 2011), $2.60 \pm 1.15 \mathrm{~m}$ (October 2014), and $2.44 \pm 1.18 \mathrm{~m}$ (October 2016; Table 2 and Fig. 2).

\subsection{Ice thickness assuming zero ice freeboard}

Another approach to estimate ice thickness assumes that snow depth is equal to the total freeboard (Kurtz and Markus, 2012), i.e., zero ice freeboard. This is informed by the view that sea ice freeboards in field observations in the Antarctic usually have means very near zero. Here, we assess the potential effect of this assumption by comparing $h_{\mathrm{i}}^{\text {lidar }}\left(h_{\mathrm{f}}^{\text {ATM }}, h_{\mathrm{f}}^{\mathrm{ATM}}\right)$ with $h_{\mathrm{i}}^{\text {lidar }}\left(h_{\mathrm{f}}^{\mathrm{ATM}}, h_{\mathrm{fs}}^{\mathrm{SR}} ;\right.$ Eq. 7). The differences for the three years show that the transect-averaged ice thicknesses could be potentially underestimated by up to a meter (Fig. 6). So, in the interior of the Antarctic ice cover, perhaps it may be more useful to use estimates of snow depth when differences of freeboards are available (i.e., ICESat-2 and CS-2) than to assume zero ice freeboard.

\section{Conclusions}

In this paper, we addressed two topics using the Weddell Sea data set acquired by Operation IceBridge and CryoSat2. First, we examined the spatial and interannual variability of total freeboard, snow depth, and sea ice thickness in three years (2011, 2014, and 2016) of repeated IceBridge surveys of a transect across the Weddell Sea. Second, the estimation of sea ice thickness, in the absence of snow depth measurements, using only freeboards from the IS-2 and nearcoincident CS-2 radar freeboards is analyzed. Here, ATM lidar freeboard is used as a proxy for ICESat-2 freeboard. Presuming that CS-2 acquisitions are available after the launch of IS-2, the relevance of this analysis pertains to the use of differences between IS-2 and CS-2 freeboards as estimates of snow depth for ice sea thickness calculations.

Of geophysical interest are the following results.

- Averaged over this Weddell Sea transect, ice thickness ranges between $2.40 \pm 1.07$ and $2.51 \pm 1.16$ (October 2011) and $2.60 \pm 1.15 \mathrm{~m}$ (October 2014) and 2.44 \pm $1.18 \mathrm{~m}$ (October 2016; Table 2 and Fig. 2). The average thicknesses are strikingly similar. As in the eastwest gradient in snow depth and freeboard, the thicker sea ice is in the more deformed ice cover in the western Weddell Sea. These OIB estimates are much higher than those reported by most drilling and ship-based measurements.

- Spatial and regional statistics of snow depth and ice thickness may be biased due to the incomplete sampling of the thin end of the snow depth distribution.

- For the three years, radar freeboards from CS-2 (i.e., uncompensated for snow thickness) sampled along the same transect are consistently higher (by up to $8 \mathrm{~cm}$ ) than those computed using IceBridge data. This sug- 
gests radar scattering that originates above the snowice interface, likely associated with saline snow in the basal layers of the snow column reported in the literature (Sect. 5).

- When only differences in lidar (ICESat-2 or ATM) and radar (CS-2) freeboards are available for the calculation of sea ice thickness, the consequence of higher than expected radar freeboard is that the sea ice thicknesses are also higher (i.e., overestimated). This can be up to $0.6 \mathrm{~m}$ thicker than those thicknesses computed using snow depths from the snow radar.

- Results also show that using differences in lidar (ICESat-2 or ATM) and radar (CS-2) freeboards for the calculation of sea ice thickness is preferable to the approach that assumes the snow depth is equal to the total freeboard, with which ice thickness here could be underestimated by up to a meter.

Data availability. The datasets from NASA's Operation IceBridge are provided by the National Snow and Ice Data Center Distributed Active Archive Center, Boulder, CO, USA (ATM L1B elevation and echo strength: https://doi.org/10.5067/19SIM5TXKPGT, Narrow swath ATM L1B elevation and echo strength: https://doi.org/10.5067/CXEQS8KVIXEI, Snow radar L1B geolocated radar echo strength profiles: https://doi.org/10.5067/FAZTWP500V70.)

Author contributions. RK and SK designed the experiments and carried them out. RK prepared the manuscript with contributions from the co-author.

Competing interests. The authors declare that they have no conflict of interest.

Acknowledgements. We thank Shirley S. Pang for her software support during the course of this work. Ronald Kwok and Sahra Kacimi carried out this work at the Jet Propulsion Laboratory, California Institute of Technology, under contract with the National Aeronautics and Space Administration.

Edited by: Christian Haas

Reviewed by: two anonymous referees

\section{References}

Dominguez, R.: IceBridge DMS L1B Geolocated and Orthorectified Images, Version 1 (2014-2015), NASA National Snow and Ice Data Center Distributed Active Archive Center, Boulder, Colorado, USA, https://doi.org/10.5067/OZ6VNOPMPRJ0, 2010.

Giles, K. A., Laxon, S. W., and Worby, A. P.: Antarctic sea ice elevation from satellite radar altimetry, Geophys. Res. Lett., 35, L03503, https://doi.org/10.1029/2007g1031572, 2008.

Koenig, L. S., Martin, S., Studinger, M., and Sonntag, J.: Polar Airborne Observations Fill Gap in Satellite Data, Eos Trans. AGU, 91, https://doi.org/10.1029/2010eo380002, 2010.

Krabill, W.: IceBridge Narrow Swath ATM L1B Elevation and Return Strength, Version 2 (updated 2016), NASA National Snow and Ice Data Center Distributed Active Archive Center, Boulder, Colorado, USA, https://doi.org/10.5067/CXEQS8KVIXEI, 2014.

Kurtz, N. T. and Markus, T.: Satellite observations of Antarctic sea ice thickness and volume, J. Geophys. Res., 117, C08025, https://doi.org/10.1029/2012JC008141, 2012.

Kwok, R.: Simulated effects of a snow layer on retrieval of CryoSat2 sea ice freeboard, Geophys. Res. Lett., 41, 5014-5020, 2014.

Kwok, R. and Cunningham, G. F.: Variability of Arctic sea ice thickness and volume from CryoSat-2, Philos. T. R. Soc. A, 373, 20140157, https://doi.org/10.1098/rsta.2014.0157, 2015.

Kwok, R. and Haas, C.: Effects of radar side-lobes on snow depth retrievals from Operation IceBridge, J. Glaciol., 61, 576-584, 2015.

Kwok, R. and Maksym, T.: Snow depth of the Weddell and Bellingshausen sea ice covers from IceBridge surveys in 2010 and 2011: An examination, J. Geophys. Res., 119, 4141-4167, 2014.

Kwok, R. and Markus, T.: Potential basin-scale estimates of Arctic snow depth with sea ice freeboards from CryoSat-2 and ICESat2: An exploratory analysis, Adv. Space Res., 62, 1243-1250, https://doi.org/10.1016/j.asr.2017.09.007, 2017.

Kwok, R., Panzer, B., Leuschen, C., Pang, S., Markus, T., Holt, B., and Gogineni, S.: Airborne surveys of snow depth over Arctic sea ice, J. Geophys. Res., 116, C11018, https://doi.org/10.1029/2011jc007654, 2011.

Kwok, R., Cunningham, G. F., Manizade, S. S., and Krabill, W. B.: Arctic sea ice freeboard from IceBridge acquisitions in 2009: Estimates and comparisons with ICESat, J. Geophys. Res., 117, C02018, https://doi.org/10.1029/2011jc007654, 2012.

Kwok, R., Kurtz, N. T., Brucker, L., Ivanoff, A., Newman, T., Farrell, S. L., King, J., Howell, S., Webster, M. A., Paden, J., Leuschen, C., MacGregor, J. A., Richter-Menge, J., Harbeck, J., and Tschudi, M.: Intercomparison of snow depth retrievals over Arctic sea ice from radar data acquired by Operation IceBridge, The Cryosphere, 11, 2571-2593, https://doi.org/10.5194/tc-112571-2017, 2017.

Leuschen, C.: IceBridge Snow Radar L1B Geolocated Radar Echo Strength Profiles, Version 2 (2014-2015), NASA National Snow and Ice Data Center Distributed Active Archive Center, Boulder, Colorado, USA, https://doi.org/10.5067/FAZTWP500V70, 2014.

Markus, T., Neumann, T., Martino, A., Abdalati, W., Brunt, K. M., Csatho, B., Farrell, S., Fricker, H. A., Gardner, A. S., Harding, D., Jasinski, M., Kwok, R., Magruder, L., Lubin, D., Morison, J., Nelson, R., Neuenschwander, A., Palm, S., Popescu, S., Shum, C. K., Schutz, B., Smith, B., Yang, Y., and Zwally, H. J.: The 
Ice, Cloud, and land Elevation Satellite-2 (ICESat-2): Science requirements, concept, and implementation, Remote Sens. Environ., 190, 260-273, https://doi.org/10.1016/j.rse.2016.12.029, 2016.

Massom, R. A., Eicken, H., Haas, C., Jeffries, M. O., Drinkwater, M. R., Sturm, M., Worby, A. P., Wu, X. R., Lytle, V. I., Ushio, S., Morris, K., Reid, P. A., Warren, S. G., and Allison, I.: Snow on Antarctic Sea ice, Rev. Geophys., 39, 413-445, 2001.

Nandan, V., Geldsetzer, T., Yackel, J., Mahmud, M., Scharien, R., Howell, S., King, J., Ricker, R., and Else, B.: Effect of Snow Salinity on CryoSat-2 Arctic First-Year Sea Ice Freeboard Measurements, Geophys. Res. Lett., 44, 10419-10426, https://doi.org/10.1002/2017g1074506, 2017.

Panzer, B., Gomez-Garcia, D., Leuschen, C., Paden, J., RodriguezMorales, F., Patel, A., Markus, T., Holt, B., and Gogineni, P.: An ultra-wideband, microwave radar for measuring snow thickness on sea ice and mapping near-surface internal layers in polar firn, J. Glaciol., 59, 244-254, 2013.
Willatt, R. C., Giles, K. A., Laxon, S. W., Stone-Drake, L., and Worby, A. P.: Field Investigations of Ku-Band Radar Penetration Into Snow Cover on Antarctic Sea Ice, IEEE T. Geosci. Remote, 48, 365-372, 2010.

Williams, G., Maksym, T., Wilkinson, J., Kunz, C., Murphy, C., Kimball, P., and Singh, H.: Thick and deformed Antarctic sea ice mapped with autonomous underwater vehicles, Nat. Geosci., 8 , 61-67, 2015.

Xie, H. J., Tekeli, A. E., Ackley, S. F., Yi, D. H., and Zwally, H. J.: Sea ice thickness estimations from ICESat Altimetry over the Bellingshausen and Amundsen Seas, 2003-2009, J. Geophys. Res., 118, 2438-2453, 2013.

Yi, D. H., Zwally, H. J., and Robbins, J. W.: ICESat observations of seasonal and interannual variations of sea-ice freeboard and estimated thickness in the Weddell Sea, Antarctica (2003-2009), Ann. Glaciol., 52, 43-51, 2011. 